\title{
THE EFFECT OF ABNORMAL BIRTH ON BLOOD CHEMISTRY DURING THE FIRST 48 HOURS OF LIFE
}

\author{
BY \\ W. W. PAYNE and P. T. ACHARYA \\ From the Department of Pathology, Queen Charlotte's Maternity Hospital, London
}

(RECEIVED FOR PUBLICATION DECEMBER 4, 1964)

This study arose out of a plan to examine the changes in blood chemistry during the first $\mathbf{4 8}$ hours of life. No attempt was made to select cases and it was only later on, when it was found that the results varied with the manner of birth, that the normal group (Acharya and Payne, 1965) was separated. The remainder were grouped into (1) forceps delivery and prolonged difficult delivery, (2) planned

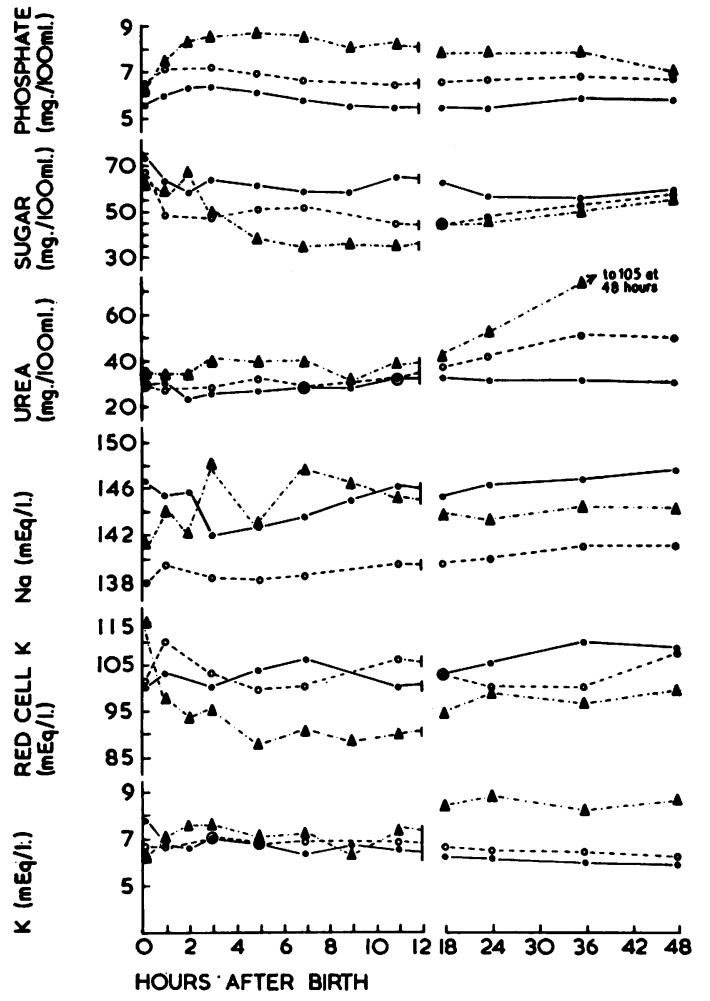

(a) caesarean section, (3) maternal toxaemia (with caesarean section), (4) maternal diabetes, (5) infants showing symptoms of respiratory distress syndrome, and (6) deaths. With so many groups the numbers in each are small, and therefore no attempt was made to calculate standard deviations of the mean. For comparison of groups, however, the mean values have been calculated. The same technique and methods have been used throughout, except that only 10 specimens of blood (instead of 12) have been collected over 48 hours, because occasionally the baby's heels became rather tender. No trouble occurred after the reduction in number of pricks. The cord was clamped at once after birth.

Fig. 1 shows the mean values for the infants from groups 1 (6 cases), 2 (4 cases), and 3 (6 cases), the mean normal values (Acharya and Payne, 1965) and the mean of 4 infants with respiratory distress

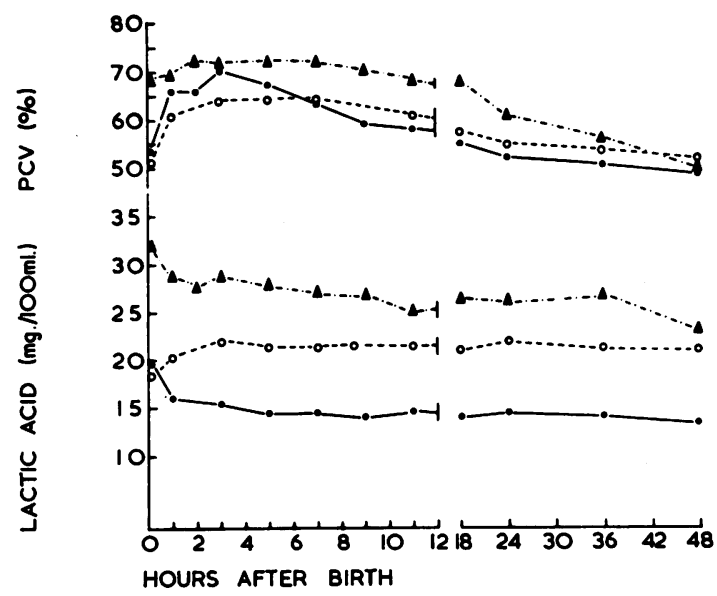

(b)

FIG. 1a and $1 \mathrm{~b}$.-Mean values in normal infants $(O)$, infants delivered by stressful obstetric procedures $(O)$, and infants with respiratory distress who survived 48 hours $(\boldsymbol{\Delta})$. (a) Plasma and red cell potassium, plasma sodium, blood urea, sugar, and phosphate.

(b) Lactic acid and PCV. 

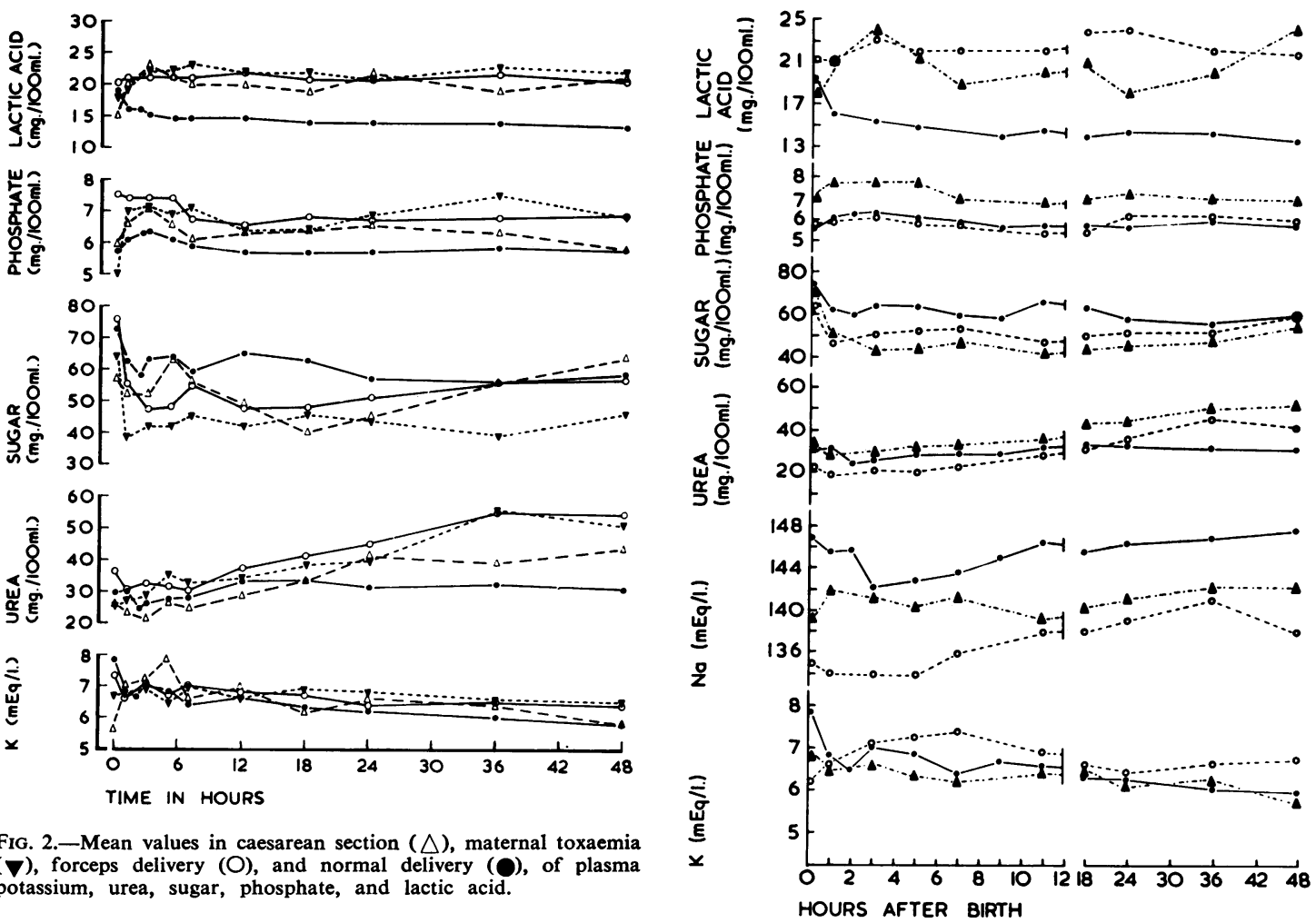

FIG. 2-Mean values in caesarean section ( $\triangle$ ), maternal toxaemia $(\nabla)$, forceps delivery $(O)$, and normal delivery (O), of plasma potassium, urea, sugar, phosphate, and lactic acid.

syndrome (RDS) who survived the first 48 hours of life.

The serum potassium shows no change in the first 12 hours but, as has also been reported by Usher (1959), it rises in the later period (18-48 hours) in the 4 cases of RDS. In contrast the serum sodium in the stressfully born infants, groups 1,2 , and 3 , is lower for the whole period but in RDS shows no wellmarked change. Blood urea shows no change in the first 12 hours but in the 18 to 48 -hour period the values in the groups 1,2 , and 3 are significantly higher than normal, and in RDS are much higher than in both normal and groups 1, 2, and 3. Sugar, after the first 3 hours, falls to lower levels in groups 1, 2, and 3 and in RDS; but by the end of 48 hours there is no material difference in the three groups. The inorganic phosphorus shows a small increase in groups 1, 2, and 3 and a well-marked increase in RDS. Lactic acid is persistently raised for the whole 48 hours in groups 1,2 , and 3. In RDS the initial value is very high but subsequently there is a small but steady decrease, though it is still high at 48 hours. The packed cell volume is raised in RDS and remains high until 36 hours of age.

In Fig. 2 the potassium, phosphorus, urea, sugar,

Fig. 3.-Comparison of mean values between normally born infants $(O)$, infants stressfully born but clinically normal $(O)$, and infants stressfully born with peripheral cyanosis $(\boldsymbol{\Delta})$.

and lactic acid levels are shown for each of the three groups 1,2, and 3 together with the normal. It will be seen that on the whole the three groups resemble each other and differ from the normal, except that the blood urea in the caesarean section group shows less change.

As many of the group 1 infants born with stress were clinically quite normal, in Fig. 3 a comparison has been made between these infants and the remainder. In the infants who were not quite normal clinically the most frequent abnormality was cyanosis of hands and feet, and this symptom has been used to characterize the group. The clinically normal stressed group shows a lower sodium, a smaller rise in urea, and a smaller fall in sugar than the cyanosed group. The lactic acid values are not significantly different, but the cyanosed group has a much higher phosphorus level than the clinically normal group where the phosphorus level does not differ from that of the normal control group.

In Fig. 4 the results from 4 infants born by caesarean section to diabetic mothers are shown. 


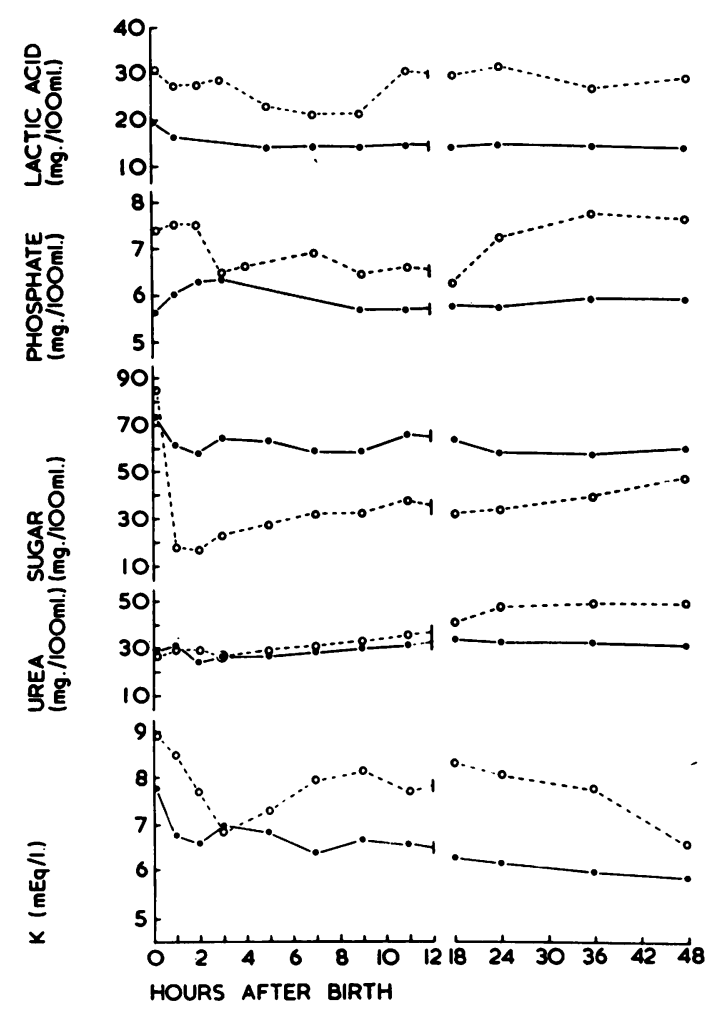

FIG. 4.-Comparison of normally born infants $(O)$ and infants born of diabetic mothers $(O)$.

They show similar departures from normal as in the previous groups, but the fall in blood sugar is much greater and the rise in potassium is also greater.

In Fig. 5a and $b$ the values obtained in 4 fatal cases of RDS are shown individually, together with the normal. It will be seen that the same type of change already recorded is present to a greater degree.

\section{Discussion}

Many factors are involved in the determination of the actual level of a given substance in the blood and our present knowledge is insufficient to give adequate explanations for all the changes observed.

The known variants at birth which could affect the blood composition can be grouped into 5 categories: (1) circulatory; (2) respiratory; (3) hormonal; (4) metabolic; and (5) environmental.

Circulation Factors. At birth the pulmonary circulation has to be established, and this entails the opening up of a large capillary bed. Owing to the physical factors involved in a flow of fluid containing small particles (Gairdner, Marks, Roscoe, and
Brettell, 1958), a layer of plasma free from particles becomes adherent to the walls of the capillaries. This is equivalent to removing a part of the plasma of the blood and causes the PCV to increase-which happens within a few minutes.

Failure to close the ductus will lead to some blood by-passing the lungs and thus to a lowering of the oxygen saturation of the arterial blood even if the lungs are fully expanded: if expansion is only partial the blood circulating through the unexpanded parts will remain venous in character and will also lower the arterial oxygen saturation. Pathological conditions in the lungs at birth may also reduce gas exchange. Hypoxia produces incomplete combustion of the acid break-down products of carbohydrate metabolism, of which lactic acid is by far the largest individual component. This decreases the $p \mathrm{H}$ and bicarbonate by causing a metabolic acidosis proportional to the degree of hypoxia.

As a result of the acidosis there will be a transfer of $\mathrm{H}$ ions from plasma into cells, with a balancing transfer of $K$ from cell to plasma as shown by the increase in plasma $\mathrm{K}$ in acidosis.

With regard to the high phosphorus values found, in anoxia, the only source of energy for essential body functions lies in the anaerobic breakdown of glucose to lactic acid. This gives some energy at the expense of increased metabolic acidosis. With the exhaustion of available carbohydrate, the individual cells become unable to maintain their functional stability, the so-called 'sodium pump' fails and the necessary electrical potentials on cell surfaces become discharged. The mitochondria of the cell, 'the power houses', discharge all their available active $\mathbf{P}$ and become disorganized; and if oxygen is not soon available the adenosine triphosphate (ATP) breaks down into its constituent parts, which escape into the circulation and cause an increase in the phosphorus, amino acids, and pentoses (McShan, Potter, Goldman, Shipley, and Meyer, 1945; Migone, 1962). This is an irreversible event and, though some organs of the body more richly endowed at birth with glycogen may survive, these cells will die, and if vital to the body, the end-result will be death to the baby. These changes are similar to those found in experimental irreversible shock, and it is suggested that the terminal stages of death in infants suffering from RDS are those of shock.

The various hormones are known to influence the chemistry of the body. The hormonal situation of the newborn is difficult to assess. In utero the foetus is not independent of its mother in its control of its endocrine glands, and, though all the necessary glands exist and are capable of activity, there is suggestive evidence that the maternal endocrine 

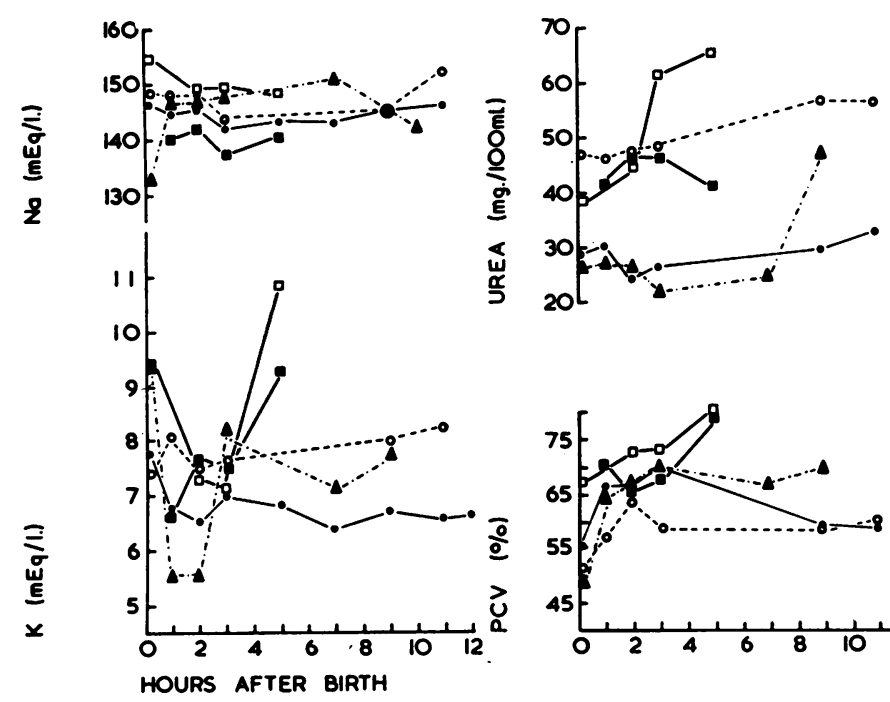

(a)
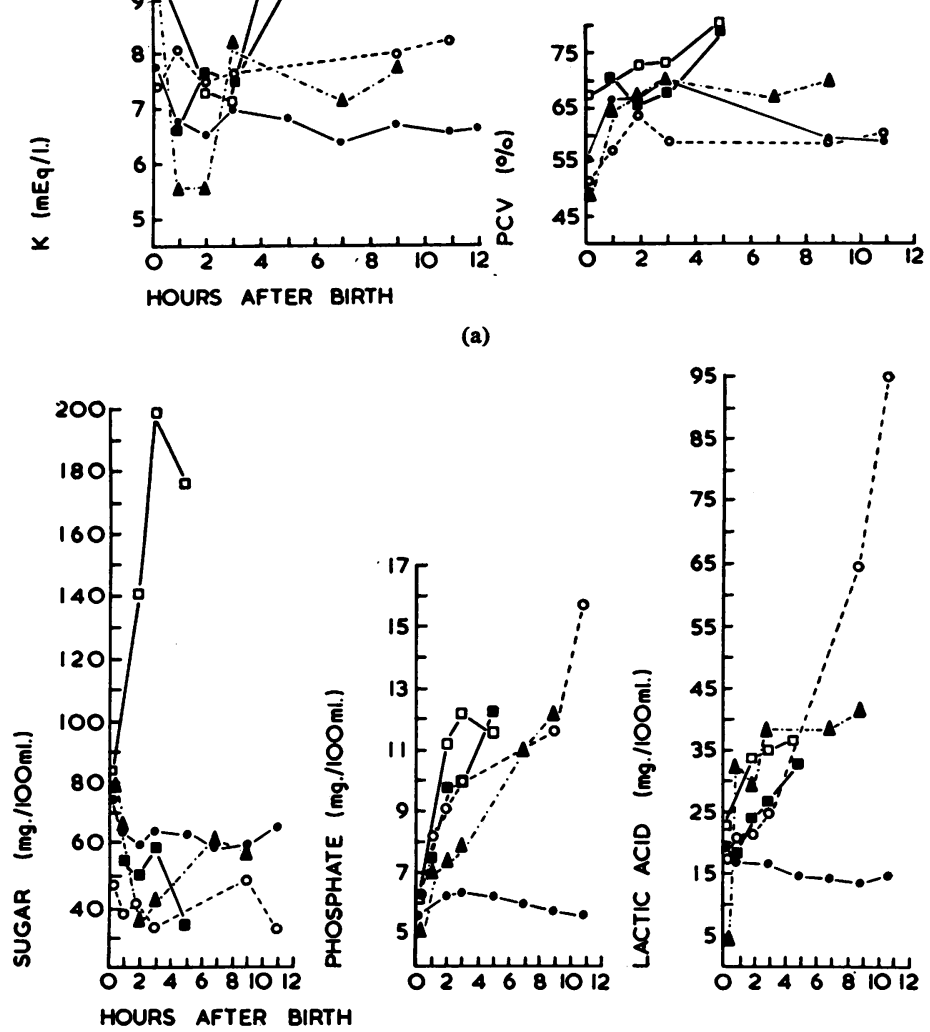

(b)

Figs. 5 ( $(a$ and $b)$.-Blood changes in 4 infants who died with respiratory distress $(O, \Delta, \square, \square)$, compared with average normal infant $(\Theta)$.

secretions enter the foetal circulation (Migeon, 1961) and to some extent inhibit the foetal gland activity. An additional complication is due to the existence of a large foetal zone in the suprarenal whose function is still unknown. It atrophies at birth and is replaced by adult type of cells which are present in small amounts in the foetal gland. The metabolism of the adrenal hormones is different in the newborn, and the urinary steroids are very different from the usual adult pattern (Cathro, Birchall, Mitchell, and Forsyth, 1963). Examination of the urine does not give as much information about the activity of the suprarenal gland as later on in life, but there is evidence that the neonatal suprarenal will respond to stimulation (Klein, 1955) by ACTH or by stressful situations.

The infant's parathyroids may also be affected by the high output of maternal parathyroid hormone required for the liberation of stored calcium by the mother during the last 2 months of pregnancy, when the calcium requirements of the foetus greatly exceed the maternal intake. Though at birth the calcium level in the cord blood is normal, there is a fairly constant fall in the neonatal calcium level during the 
next 24-48 hours (Acharya and Payne, 1965) but only occasionally a fall low enough to cause tetany. At the same time, the blood inorganic phosphate level is high when the urinary phosphate excretion is low, suggesting an effect of low level of parathormone in the renal tubules (Smith, 1959).

Metabolic Effects. Since from the moment of birth the infant becomes responsible for its own energy needs, and is indeed using energy in amounts varying with its environment, it has to rely on its stores of energy-producing substances; it will be many hours before its alimentary canal will be able to supply its daily needs. The main stores of energy are glycogen (Shelley, 1964) and fat (Widdowson and Spray, 1951) and a full-term infant is well endowed with both. Not all organs of the body can store energy, and so the infant will have to keep the levels of circulating energy producing substances at a level high enough for their needs. The biggest organ requiring energy is the brain, and the nerve cells do not appear to be able to utilize fat but need carbohydrate or its metabolites lactic and pyruvic acid. The mechanisms for the maintenance of a suitable level are similar to those of the adult, e.g. adrenaline and possibly glucocorticoids; but a bigger stimulus appears to be needed to bring the blood sugar up to a safe level. It seems that in the first few days of life the metabolism of the infant can maintain itself at a lower level of blood sugar than in the child or adult, but sometimes there is a difficulty in maintaining even this low level and the efforts needed may cause symptoms such as 'jitteriness', possibly a side-effect of the action of adrenaline, or actual fits, which are probably a 'final demand note' from the brain to the tissues. Fits will force the muscles to give up some of their carbohydrate stores in the form of lactic acid. Excess ACTH may also be called forth to increase the glucocorticoids, with probably also an increased mineralocorticoid effect as shown by alteration in the sodium potassium levels.

Muscles can use their stored glycogen as a source of energy, even in the absence of oxygen, but with adequate oxygen they will use free fatty acids equally as well. Normally the level of fuel is kept as constant as possible (Randle, Garland, Hales, and Newsholme, 1963) and there is an inverse relation between free fatty acid and glucose. This relation is, however, not maintained in the presence of extra insulin or adrenaline or corticoids.

In the stressed infants and in infants with low food stores, the need for fuel, and also increased corticoid secretion, leads to protein breakdown giving rise to increased blood amino acids and ultimately to increased urea production. Some of the amino acids can be turned into glucose and used as such, and it is possible that the cerebral cells can use unaltered amino acids as a source of energy. Apart from breakdown of protein in response to stress, in the absence of protein food the level of amino acid will need to be maintained to enable cell regeneration and growth to occur, and this can only be done by robbing Peter to pay Paul-i.e. less important proteins, such as serum albumin and skeletal muscle tissue, will be broken down in order to build up essential proteins. It has also been shown (Giordano, 1963) that urea can be utilized as a source of nitrogen for the non-essential amino acids-the need for essential amino acids will demand tissue protein breakdown until an adequate intake is achieved.

Conclusions. In the light of the preceding discussion, it is possible to guess at the causes of the variations that occurred.

The variations in potassium and sodium over the 48 hours tend to be reciprocal, but the actual levels of potassium are affected by the $p \mathrm{H}$, by glycogen utilization, and by tissue breakdown. Sodium variations are affected only by the element of concentration due to loss of water, and the low values can most simply be related to the level of mineralocorticoids. Urea does not materially change during the first 12 hours, and no difference between normal and stressed groups occurs, but from 18 hours onward the greater the stress the higher is the urea and this can only be due to a greater amount of tissue breakdown. With sugar the difference between the normal and the stressed groups is most marked in the more stressed, but this difference gets less during the second day. This may well be due to gluconeogenesis from tissue protein, as the increase of urea occurs at this time. The rise in the phosphate could be due to $\mathrm{CO}_{2}$ retention (Cordier and Piery, 1955), to liberation from the cell when glycogen is broken down to glucose, or to tissue breakdown. However, this last factor is not a likely cause since there is no increase in the blood phosphate in the second 24 hours at a time when tissue breakdown is at a maximum and, indeed, its highest level is during the earliest hours of life when glycogen is being used most rapidly.

The lactic acid level shows the most striking differences. In all the stressed groups, the level is higher throughout the whole 48 hours, except at birth when the level is also high in the normals. The two most common causes for a high lactic acid are low oxygen levels and muscular exercise. As there was no observable difference in muscular activity between the difficult labour group and the 
normally born group, the probable cause of the continued rise in lactic acid is a lack of oxygen, due to some shunting in the circulation; to a failure of the lungs to effect gaseous exchange in the RDS group; or to some degree of peripheral stasis, which would be shown as cyanosis of the extremities, as actually seen in about half of the stressed cases and in none of the normal cases. However, if the stressed group is divided into those with and those without cyanosis (see Fig. 3), it will be seen that those with no cyanosis had, in fact, a slightly higher lactic acid level, so peripheral stasis is probably not a cause of raised blood lactic acid.

A study of the changes in the blood chemistry of the 4 fatal cases of RDS shows a similar, but greater, departure from the normal as in the stressed group (Fig. 5a and b).

The potassium rises terminally in all, but not to a level that is lethal in the newborn infant, who seems to tolerate much higher potassium levels than older children and adults. The blood urea rises earlier but has not time to become very high. Sodium shows no material change. The most striking changes are in the sugar, which is low in 3 and very high in 1 , in the phosphorus which rises rapidly, and in the lactic acid which also is very high.

Can any treatment reverse these changes? Up to the present, in the similar changes in animal experimental shock, there is no way in which fully developed shock can be corrected, but prevention by various techniques has had more success. It is by studying this aspect of the treatment of severe RDS that improved results may be obtained.

\section{Summary}

A group of infants, born by forceps or caesarean section, of normal or toxaemic or diabetic mothers, was studied in respect of the variation in the blood levels of sodium, potassium, chloride, glucose, urea, inorganic phosphate, lactic acid, and total plasma protein during the first 48 hours of life. The results were compared with those from normal newborn infants, and certain differences were found. Two other groups of babies suffering from the respiratory distress syndrome, one group of those who recovered, the other of those who died, were also studied, and similar but greater differences noted.

It is a pleasure to acknowledge the help given us by Professor J. H. Pinkerton, Dr. A. White Franklin, and Dr. A. P. Norman, and the ward sisters and staff, especially Sister Penrice and Sister Fairbrother, and to Dr. B. C. Mukerji for technical help. We are indebted to the Board of Governors of the Hospital for a grant enabling this work to be done, and to the Medical Research Council for a personal grant to one of us (P.T.A.). Our thanks are also due to Professor J. P. M. Tizard, Dr. J. A. Davis, and Dr. J. W. Scopes for much help in the preparation of this paper.

\section{REFERENCES}

Acharya, P. T., and Payne, W. W. (1965). Blood chemistry of normal full-term infants in the first 48 hours of life. Arch. Dis. Childh., 40, 430.

Cathro, D. M., Birchall, K., Mitchell, F. L., and Forsyth, C. C. (1963). The excretion of neutral steroids in the urine of newborn infants. J. Endocr., 27, 53.

Cordier, D., and Piery, Y. (1955). Influence de l'anoxie, de l'asphyxie et de l'hypercarbie sur la teneur en phosphore inorganique du plasma du rat. Relations entre la phosphatémie et l'absorption intestinale des phosphates minéraux. J. Physiol. (Paris), 47, 147.

Gairdner, D., Marks, J., Roscoe, J. D., and Brettell, R. O. (1958). The fluid shift from the vascular compartment immediately after birth. Arch. Dis. Childh., 33, 489.

Giordano, C. (1963). Use of exogenous and endogenous urea for protein synthesis in normal and uremic subjects. J. Lab. clin. Med., 62, 231.

Klein, R. (1955). Adrenal function in infants and children, p. 31. Report of 13 th M. \& R. Pediatric Research Conference, Columbus, Ohio.

McShan, W. H., Potter, Van R., Goldman, A., Shipley, E. G., and Meyer, R. K. (1945). Biological energy transformations during shock as shown by blood chemistry. Amer. J. Physiol., 145, 93.

Migeon, C. J. (1961). The endocrine function of the newborn. In Ciba Foundation Symposium on Somatic Stability in the Newly Born, ed. G. E. W. Wolstenholme and M. O'Connor, p. 215. Churchill, London.

Migone, L. (1962). In Shock: Pathogenesis and Therapy, ed. D. K. Brock, p. 76. Springer, Berlin.

Randle, P. J., Garland, P. B., Hales, C. N., and Newsholme, E. A. (1963). The glucose fatty-acid cycle. Its role in insulin sensitivity and the metabolic disturbances of diabetes mellitus Lancet, 1, 785.

Shelley, H. J. (1964). Carbohydrate reserves in the newborn infant. Brit. med. J., 1, 273.

Smith, C. A. (1959). The Physiology of the Newborn Infant, 3rd ed, p. 392. Blackwell, Oxford.

Usher, R. (1959). The respiratory distress syndrome of prematurity. I. Changes in potassium in the serum and the electrocardiogram and effects of therapy. Pediatrics, 24, 562.

Widdowson, E. M., and Spray, C. M. (1951). Chemical development in utero. Arch. Dis. Childh., 26, 205. 